\title{
Bulk Hyperpolarization of Inorganic Materials
}

\author{
Snædís Björgvinsdóttir ${ }^{\S}$ and Lyndon Emsley* \\ §SCS-DSM Award for best virtual poster in Physical Chemistry
}

\begin{abstract}
Solid-state NMR spectroscopy is a well-established method to obtain atomic-level information about the structure of inorganic materials, but its use is often limited by low sensitivity. We review how solvent generated dynamic nuclear polarization can be used to increase sensitivity in solid-state NMR of inorganic materials, with emphasis on our recent method for hyperpolarization of proton-free bulk. We use selected examples to show how overall gains in sensitivity can be observed in both the surface and bulk spectra of inorganic compounds such as lithium titanate. The hyperpolarization methods reviewed here can be used to improve NMR sensitivity for a range of inorganic materials.
\end{abstract}

Keywords: Dynamic nuclear polarization · Inorganic materials $\cdot$ Nuclear magnetic resonance $\cdot$ Spin diffusion

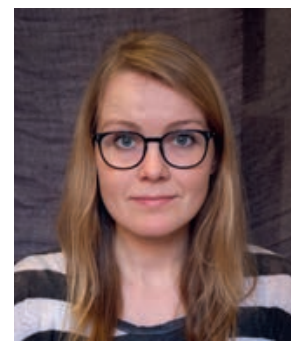

Sncedís Björgvinsdóttir obtained her BSc and MSc degrees in chemistry from the University of Iceland. She recently finished her $\mathrm{PhD}$ from the Ecole Polytechnique Fédérale de Lausanne (EPFL), where she worked in the group of Lyndon Emsley. She is interested in the development of dynamic nuclear polarization methods to increase sensitivity in solid-state nuclear magnetic resonance.

\section{Introduction}

Solid-state nuclear magnetic resonance (NMR) spectroscopy is an analytical technique which directly probes molecular symmetry and structure at nuclei, and consequently provides information about the atomic-level structure and dynamics of materials. ${ }^{[1]}$ Understanding how the properties of materials are related to their structure is one of the most important aspects of chemistry and materials science today, and solid-state NMR is especially useful for characterization of disordered, amorphous or heterogeneous solids. ${ }^{[2]}$

One of the main drawbacks of solid-state NMR is its inherently low sensitivity, caused by the relatively low polarization of nuclear spins. This is especially problematic in the case of many inorganic materials, where low concentrations and low gyromagnetic ratios $\left(\gamma_{\mathrm{I}}\right)$ of the magnetically active nuclei further decrease the sensitivity. As a result, even one-dimensional NMR experiments of nuclei with low sensitivity can be very time consuming.

Dynamic nuclear polarization (DNP) is a method to increase spin polarization, and has been proven to provide significant signal enhancements in solid-state magic-angle spinning (MAS) NMR experiments. DNP is the transfer of large electron spin polarization of unpaired electrons to nearby nuclei, achieved by microwave irradiation near to the electron paramagnetic resonance (EPR) frequency. ${ }^{[3]}$
Here we focus on the hyperpolarization of inorganic materials, and explain how sensitivity in the NMR spectra of both surface and bulk can be increased. The methods discussed are based on impregnation DNP, where the source of unpaired electrons is a stable organic radical which is added exogenously to the sample of interest as a part of a wetting phase. Upon microwave irradiation, the hyperpolarization generated in the wetting phase can be selective transferred to the surface of the target material and detected, resulting in NMR spectra of the surface of the material.[4] Alternatively, the hyperpolarization can be transported from its origin near the surface by spin diffusion, in a process called hyperpolarization relay. ${ }^{[5]}$ In particular, we discuss a strategy which has been shown to efficiently hyperpolarize the bulk of inorganic materials. [6]

As a selected example of how these methods work, we review our recent work on lithium titanates, which are of interest as anode materials in batteries. ${ }^{[7]}$ We use $\mathrm{Li}_{2} \mathrm{TiO}_{3}$ as an example to show how high sensitivity ${ }^{7} \mathrm{Li}$ and ${ }^{6} \mathrm{Li}$ surface spectra can be recorded with cross-polarization ${ }^{[8]}$ (CP) MAS. We also go over how sensitivity in bulk spectra can be improved using a combination of impregnation DNP and slow spin diffusion between lithium nuclei. As an example, an overall gain in sensitivity of around a factor 60 for the ${ }^{6} \mathrm{Li}$ bulk spectrum of $\mathrm{Li}_{2} \mathrm{TiO}_{3}$ was measured.

\section{DNP of Inorganic Materials}

Impregnation DNP was introduced around 10 years ago as a method to improve the sensitivity in NMR experiments of powdered materials, ${ }^{[4 a]}$ and is now one of the main areas of application of MAS DNP. In general, this is achieved by impregnating a microcrystalline solid material (such as the one in Fig. 1a) with a small amount of radical containing solution. The radical solution is chosen so that it dissolves the radical (Fig. 1b), but not the analyte, as shown schematically in Fig. 1c. Significant effort has been put into optimization of both the radical itself and the sample formulation. ${ }^{[9]}$ 
Most commonly, the formulated sample is packed in a solidstate MAS rotor, and inserted into a precooled DNP probe. The DNP experiments are then carried out as the sample is spun at temperatures around $90 \mathrm{~K}$. In order for microwaves to be delivered to the sample, the NMR probe needs to be coupled to a highpower microwave source capable of outputting power at an EPR frequency corresponding to the field of the magnet.[10]

The DNP signal enhancements provided by DNP can be evaluated by the enhancement factor, $\varepsilon$, which is determined by the ratio of the NMR signal intensities in spectra acquired with and without microwave irradiation $\left(\varepsilon=I_{\text {on }} / I_{\text {off }}\right)$. NMR signal intensities are directly related to the polarization of the nuclei. Relative to its initial Boltzmann polarization, the maximum theoretical enhancement of a given nucleus corresponds to the ratio of the electron and nuclear gyromagnetic ratios. As an example, the maximum enhancement of ${ }^{1} \mathrm{H}$ is around 660 and around 2600 for ${ }^{13} \mathrm{C}$, corresponding in each case to the ratio $\gamma_{e} / \gamma_{n}$.

Figs 1d and 1e show examples of DNP enhancement factors measured for the ${ }^{7} \mathrm{Li}$ and ${ }^{6} \mathrm{Li} \mathrm{CP}$ MAS spectra of a microcrystalline sample of $\mathrm{Li}_{2} \mathrm{TiO}_{3}$ impregnated with a $16 \mathrm{mM}$ solution of TEKPol radical in tetrachloroethane (TCE). ${ }^{[11]}$ A klystron microwave source with an output power of around $5.2 \mathrm{~W}$ was used to transfer the high electron polarization of the radicals to protons in the TCE, resulting in a ${ }^{1} \mathrm{H}$ DNP enhancement of around 400. Since this material is proton-free, the hyperpolarization does not transfer to the material spontaneously (as is the case in relayed DNP). Instead, CP can be used to transfer the high polarization generated on protons in the wetting phase to ${ }^{7} \mathrm{Li}$ and ${ }^{6} \mathrm{Li}$ nuclei close to the surface of the $\mathrm{Li}_{2} \mathrm{TiO}_{3}$ particles. This approach, where the surface of a material is hyperpolarized selectively is called DNP surface-enhanced NMR spectroscopy (sometimes abbrevi-

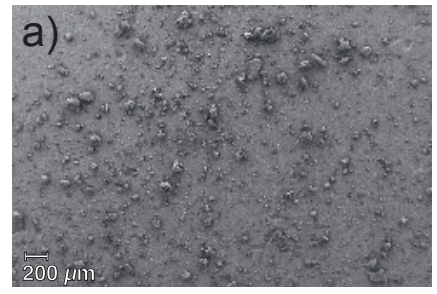

b)

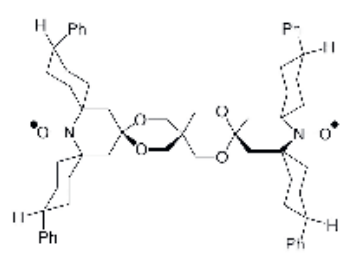

c)

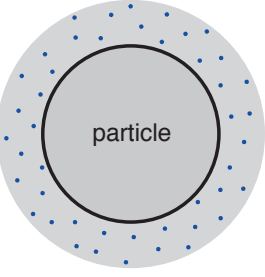

- polarizing agent

microwaves wr hyperpolarization low high

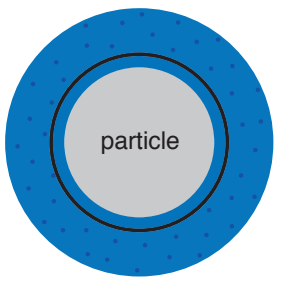

d)

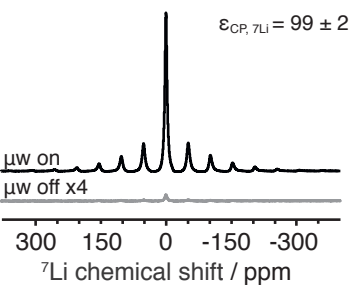

e)

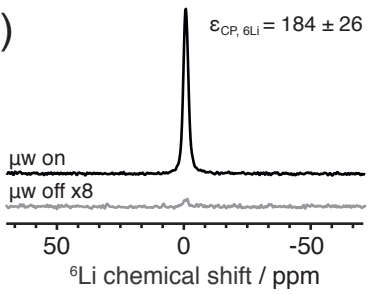

Fig. 1. Dynamic nuclear polarization of an inorganic material. (a) SEM image of ground $\mathrm{Li}_{2} \mathrm{TiO}_{3}$ powder. (b) The molecular structure of the biradical polarizing agent TEKPol. ${ }^{[1 \mathrm{a}]}$ (c) Schematic representation of a particle where the surface signals are enhanced with hyperpolarization. (d) DNP enhanced ${ }^{1} \mathrm{H}-{ }^{7} \mathrm{Li}$ CP MAS spectrum of $\mathrm{Li}_{2} \mathrm{TiO}_{3}$ compared to a spectrum of the same sample without microwave irradiation. (e) ${ }^{1} \mathrm{H}-{ }^{6} \mathrm{Li}$ CP MAS spectra of $\mathrm{Li}_{2} \mathrm{TiO}_{3}$ with and without microwave irradiation. $\mathrm{Fi}$ gure adapted from refs $[6 \mathrm{~b}, \mathrm{c}]$. ated DNP SENS). ${ }^{[4]}$ The process is shown schematically in Fig. $2 \mathrm{a}$, along with the pulse sequence used to acquire the surface selective spectra in Figs 1d and 1e. A more detailed discussion about DNP SENS and its applications can be found elsewhere.[12]

Relayed DNP targets nuclei further away from the polarizing agent, such as the bulk of the material. The relay of hyperpolarization relies on the presence of spin diffusion in the sample. ${ }^{[5]}$ Spin diffusion is the transfer of polarization through space, mediated through homonuclear dipole-dipole interactions. The process derives its name from the fact that it can on a large scale be considered as analogous to thermal diffusion. ${ }^{[13]}$ Methods to hyperpolarize the bulk of solid materials containing protons (where spin diffusion is fast) are well established, ${ }^{[5]}$ while NMR of proton-free bulk materials remains challenging in many cases. This is particularly true for compounds where nuclear relaxation times $\left(T_{1}\right)$ are long, and when isotopic enrichment or paramagnetic doping to enhance relaxation rates are not practical. We have recently introduced a strategy to hyperpolarize the bulk of inorganic materials, where the relayed DNP method is extended to proton-free inorganic materials. ${ }^{[6]}$

For inorganic materials without protons in the bulk, such as lithium titanates, relay can potentially start from nuclei near the surface as seen in Fig. 2c. The surface hyperpolarization is achieved in the same way as described before, through impregnation with a radical containing solution, followed by hyperpolarization of lithium nuclei near the surface. The surface-generated hyperpolarization can then be transported towards the bulk of the material by spontaneous homonuclear spin diffusion between low- $\gamma$ nuclei, if given enough time to do so. Spin diffusion between lower- $\gamma$ nuclei is expected to be slow due mainly to weak dipolar couplings, but has been confirmed to be present in various different compounds with long $T_{1}$ relaxation times, even at MAS rates above $10 \mathrm{kHz}{ }^{[6 a]}$ This is discussed further in section 4 .

Table 1 shows the estimated diffusion coefficients, $D$, for several different nuclei, underlining that spin diffusion between weakly magnetic nuclei is predicted to be slow. The spin diffusion coefficients are scaled from the measured $D$ for ${ }^{19} \mathrm{~F}$ in a static single crystal of $\mathrm{CaF}_{2}, D=710 \mathrm{~nm}^{2} \mathrm{~s}^{-1}$, which is similar to that for ${ }^{1} \mathrm{H}-{ }^{1} \mathrm{H}$ spin diffusion in rigid organic solids. ${ }^{[14]}$ The scaling is done using the relationship $D \propto \sqrt[3]{c} \gamma_{I}^{2}$ where $c$ is the concentration of nuclei and $\gamma_{\mathrm{I}}$ is the gyromagnetic ratio. ${ }^{[15]}$ The diffusion length $\sqrt{D T_{1}}$ then corresponds to the distance that polarization can travel from its source. The values reported in Table 1 are approximate upper limits, since the estimated diffusion coefficient for a static sample is used in combination with longitudinal relaxation constants $T_{1}$ which are measured at $90 \mathrm{~K}, 8 \mathrm{kHz}$ MAS rate, and $9.4 \mathrm{~T}$ field strength. The diffusion coefficients scale approximately as $1 / v_{R}$ with the MAS rate, as dipolar interactions are averaged out, and in addition many other factors can affect the rate of spin diffusion. ${ }^{[16]}$ The diffusion lengths are therefore likely overestimated.

Building on the presence of spin diffusion in these materials (as discussed below in section 4), we introduced a method for hyperpolarization of the bulk of inorganic materials, based on a combination of impregnation DNP, continuous replenishing of surface hyperpolarization, and slow spin diffusion between relatively weakly magnetic nuclei such as ${ }^{31} \mathrm{P}$ and ${ }^{119} \mathrm{Sn} \cdot{ }^{[6 a, b]}$ As shown in Figs $2 \mathrm{c}$ and $2 \mathrm{e}$ the hyperpolarization is maintained at the surface of the material either by direct DNP of the weakly magnetic nuclei, or by repeated bursts of cross polarization from protons in the wetting phase. Provided that bulk $T_{1}$ values are long enough, even slow spin diffusion can then transfer the surface-generated hyperpolarization to the bulk. This can result in spectra which exceed the sensitivity of conventional solid-state NMR. This is discussed in more detail in the following section, where lithium titanate is used as an example. A more detailed discussion about maximizing bulk hyperpolarization by tuning the different parameters of the pulse sequence in Fig. $2 \mathrm{f}$ can be found in ref. [6b]. 
Fig. 2. Schematic representation of a lithium titanate particle impregnated with a radical containing solution. The particle can be hyperpolarized in three different ways using the pulse sequences shown next to each schematic. a) Particle surface is polarized by CP from protons near the surface. b) Pulse sequence for DNSSENS. c) Direct polarization of surface lithium nuclei, followed by spin diffusion. d) Pulse sequence for direct DNP. e) Repeated hyperpolarization of surface ${ }^{6} \mathrm{Li}$ nuclei by $\mathrm{CP}$, followed by spin diffusion. f) Pulse sequence using multiple contact CP. Figure partially adapted from ref. [6b]. a)

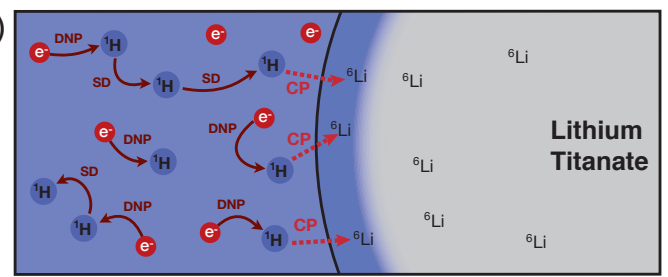

C)

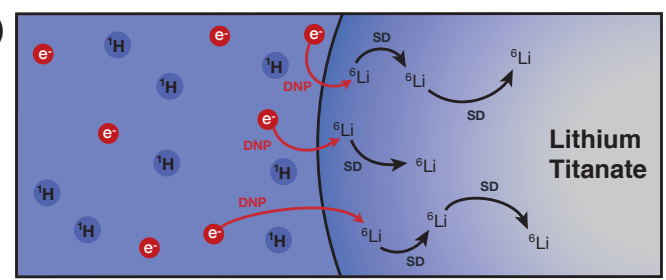

e)

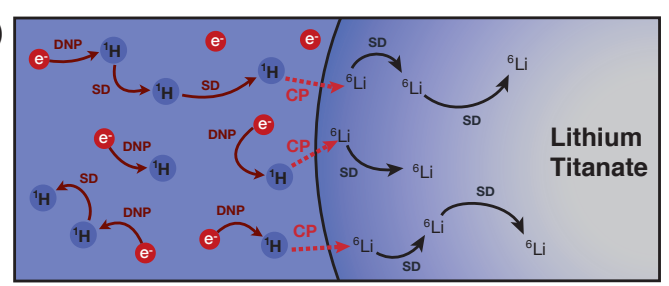

b)

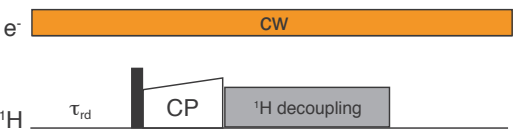

$\mathrm{Li}$

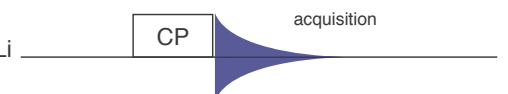

d)

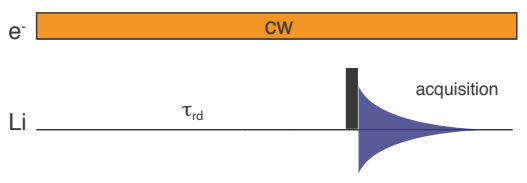

f) e

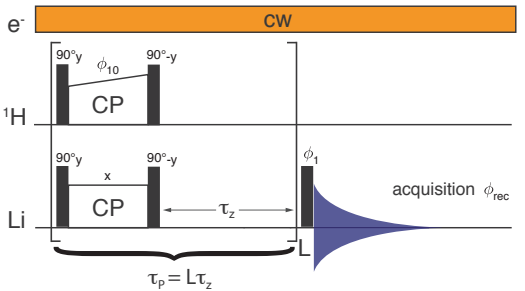

Table 1. Estimated diffusion coefficients and diffusion lengths for homonuclear spin diffusion in different inorganic materials.

\begin{tabular}{|l|r|r|r|r|}
\hline & $c(\mathrm{M})$ & $D\left(\mathrm{~nm}^{2} \mathrm{~s}^{-1}\right)$ & \multicolumn{1}{|c|}{$T_{1}(\mathrm{~s})$} & $\sqrt{D T_{1}}(\mathrm{~nm})$ \\
\hline${ }^{19} \mathrm{~F}$ in $\mathrm{CaF}_{2}$ & 81.5 & $710^{\mathrm{a}}$ & $115^{\mathrm{a}}$ & 286 \\
\hline${ }^{7} \mathrm{Li} \mathrm{in} \mathrm{Li}_{2} \mathrm{TiO}_{3}$ & 28.9 & 85.8 & 70 & 77.5 \\
\hline${ }^{6} \mathrm{Li} \mathrm{in} \mathrm{Li}_{2} \mathrm{TiO}_{3}$ & 2.3 & 5.3 & 4382 & 152 \\
\hline${ }^{7} \mathrm{Li} \mathrm{in} \mathrm{Li}_{4} \mathrm{Ti}_{5} \mathrm{O}_{12}$ & 7.1 & 53.7 & 942 & 225 \\
\hline${ }^{6} \mathrm{Li} \mathrm{in} \mathrm{Li}_{4} \mathrm{Ti}_{5} \mathrm{O}_{12}$ & 0.6 & 3.3 & 13100 & 208 \\
\hline${ }^{119} \mathrm{Sn}$ in $\mathrm{SnO}_{2}$ & 4.0 & 41 & 500 & 141 \\
\hline
\end{tabular}

a The measured diffusivity and $T_{1}$ of ${ }^{19} \mathrm{~F}$ polarization in a single crystal of $\mathrm{CaF}_{2}{ }^{[14]}$ The diffusivity is measured along the [001] direction.

\section{Improving Sensitivity}

Although the enhancement factor, $\varepsilon$, is often a convenient way to evaluate the efficiency of a DNP experiment, it does not take into account all of the factors associated with doping a sample with a paramagnetic species and irradiating it with high powers of microwaves. The factor $\varepsilon$ does not take into account effects such as signal quenching, sample dilution, or changes in temperatures or relaxation time constants. ${ }^{[17]}$ For a direct comparison of a DNP enhanced spectrum to a MAS NMR spectrum without DNP we use sensitivity ratios to evaluate the gains obtained, where the sensitivity is defined as signal-to-noise ratio per unit square root of time per milligram: sensitivity $=(\mathrm{SNR} / m) / \operatorname{sqrt}(T)$, where $m$ is the mass of the compound and $T$ is the experiment time. In this way, the sensitivity of a DNP spectrum can be compared to the sensitivity of a spectrum of the same compound without the presence of radicals, potentially at different temperature or even magnetic field, i.e. the experiment which would have been done without DNP capabilities.

${ }^{7} \mathrm{Li}$ and ${ }^{6} \mathrm{Li}$ spectra of $\mathrm{Li}_{2} \mathrm{TiO}_{3}$ are shown in Figs $3 \mathrm{a}$ and $3 \mathrm{~b}$. The spectra are acquired using the methods shown in Fig. 2. Fig. 3a shows the difference between the DNP enhanced surface spectrum, recorded with ${ }^{1} \mathrm{H}-{ }^{7} \mathrm{Li} \mathrm{CP}$, and the ordinary direct ${ }^{7} \mathrm{Li}$ spec- trum acquired without DNP, which is dominated by signal from the bulk. The surface-selective spectrum (DNP CP) is broader than the bulk spectrum (DNP direct) as seen by the linewidths and the more extended sideband pattern, indicating the presence of environments that are more anisotropic than the bulk environments.

Sensitivity comparison between the different ${ }^{7} \mathrm{Li}$ spectra is shown in Fig. 3c, where the reference experiment can be considered to be the conventional low temperature MAS spectrum of the undoped material. ${ }^{7} \mathrm{Li}$ has a relatively high gyromagnetic ratio, as well as a natural abundance of $92.3 \%$ and as a result obtaining a spectrum with a high SNR is usually not challenging. Compared to the spectrum of the undoped material, there is only a slight increase in sensitivity using the direct DNP approach. The experiments were performed at a MAS rate of $8 \mathrm{kHz}$, and they are sensitivity optimized, which means that the recovery delay is set according to the measured longitudinal relaxation times, $T_{1}$, or the DNP build-up times $T_{\mathrm{B}}$. The relaxation times measured for $\mathrm{Li}_{2} \mathrm{TiO}_{3}$ are $T_{1,7 \mathrm{Li}}=70 \mathrm{~s}$ and $T_{\mathrm{B}, 1 \mathrm{H}}=3.5 \mathrm{~s}$. Surfaces are often challenging since atoms on the surface make up a very small fraction of the total volume of the sample, but here we get high sensitivity ${ }^{1} \mathrm{H}-{ }^{7} \mathrm{Li}$ spectrum of the surface.

Fig. $3 \mathrm{~d}$ shows how sensitivity in the ${ }^{6} \mathrm{Li}$ spectra of $\mathrm{Li}_{2} \mathrm{TiO}_{3}$ can be very significantly increased with impregnation DNP. Due to the low $\gamma_{\mathrm{I}}$, long $T_{1}$, and natural abundance of ${ }^{6} \mathrm{Li}$ nuclei, the sensitivity in the conventional spectrum is low. Direct DNP of ${ }^{6} \mathrm{Li}$ shows a gain in sensitivity of around a factor of 15 . This can be improved even further by using the multiple-contact CP strategy of Fig. 2e, which here provides a sensitivity gain of almost a factor of 60. The increase in sensitivity here over that of direct DNP indicates that ${ }^{6} \mathrm{Li}$ hyperpolarization is relayed in $\mathrm{Li}_{2} \mathrm{TiO}_{3}$ (which will be discussed in the following section). A spectrum with excellent sensitivity is also generated by ${ }^{1} \mathrm{H}-{ }^{6} \mathrm{Li} \mathrm{CP}$. As seen in Fig. $3 \mathrm{~b}$, the surface spectrum of the compound is broader than the bulk spectrum, and it is also slightly shifted to the left.

A similar analysis for a different lithium titanate, $\mathrm{Li}_{4} \mathrm{Ti}_{5} \mathrm{O}_{12}$, can be found in the original work. ${ }^{[6 c]}$ This compound has a lower lithium concentration than $\mathrm{Li}_{2} \mathrm{TiO}_{3}$ and the longitudinal relaxation times are also longer, as reported in Table 1, making it a more challenging case for solid-state NMR, and even better suited to the relayed DNP approach here. 

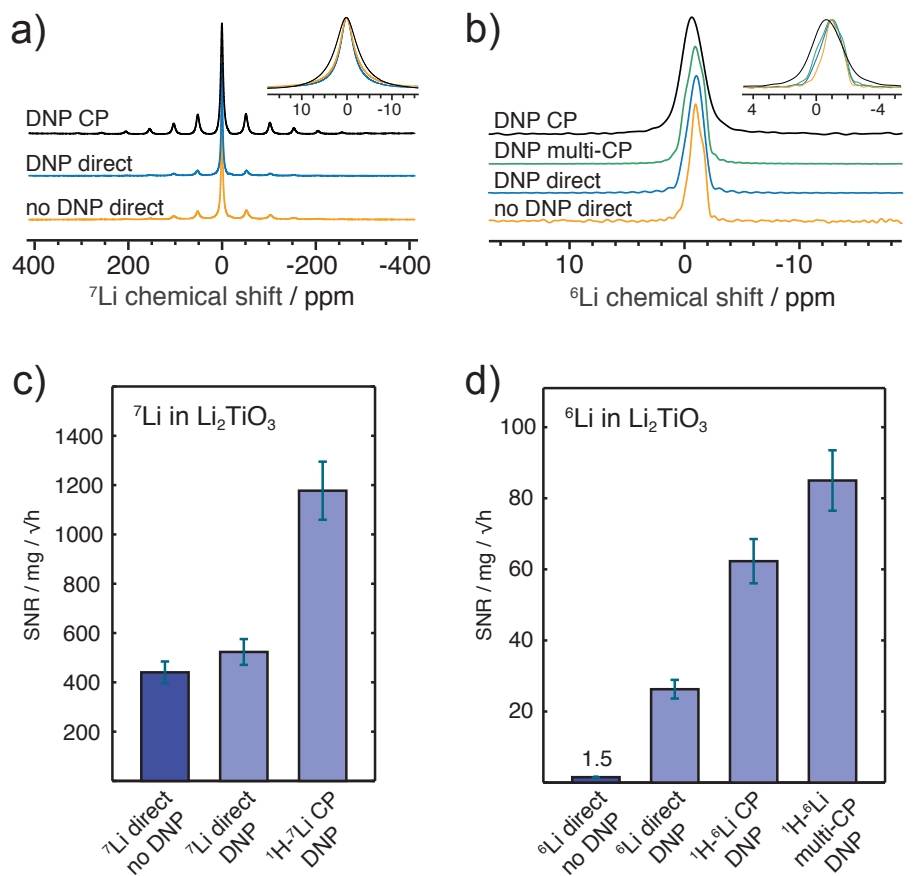

Fig. 3. MAS spectra and normalized NMR sensitivities measured for $\mathrm{Li}_{2} \mathrm{TiO}_{3}$. (a) DNP enhanced ${ }^{1} \mathrm{H}-{ }^{7} \mathrm{Li} C P$ spectrum, as well as direct ${ }^{7} \mathrm{Li}$ spectra with and without DNP. (b) DNP enhanced ${ }^{1} \mathrm{H}-{ }^{6} \mathrm{Li} \mathrm{CP}$ and multiCP spectra and direct ${ }^{6} \mathrm{Li}$ spectra with and without DNP. The spectra are scaled to the same intensity. Sensitivity comparison between different (c) ${ }^{7} \mathrm{Li}$ and (d) ${ }^{6} \mathrm{Li}$ spectra of $\mathrm{Li}_{2} \mathrm{TiO}_{3}$. Figure reproduced from ref. [6c].

In general, we have shown that this method can increase the sensitivity in bulk spectra of a range of inorganic compounds of up to a factor 85 so far. In addition to ${ }^{6} \mathrm{Li} /{ }^{7} \mathrm{Li}$ spectra of lithium titanates it has been applied to ${ }^{31} \mathrm{P}$ spectra of $\mathrm{GaP},{ }^{113} \mathrm{Cd}$ spectra of CdTe, ${ }^{29} \mathrm{Si}$ spectra of $\alpha$-quartz, and ${ }^{119} \mathrm{Sn}$ spectra of powdered $\mathrm{SnO}_{2} \cdot{ }^{\cdot 6 a, b]}$

\section{Spin Diffusion}

Homonuclear spin diffusion is driven by nuclear dipolar coupling as mentioned in section 2. The strength of this coupling diminishes greatly with lower nuclear gyromagnetic ratios and increasing internuclear distances. Exchange of magnetization through mutual energy-conserving spin flip-flops is usually lessened further when dipolar couplings are additionally averaged out by sample rotation, or when chemical shift differences are large. ${ }^{[13]}$ For these reasons, spin diffusion between nuclei other than ${ }^{1} \mathrm{H}$ and ${ }^{19} \mathrm{~F}$ is often thought to be negligible, especially under MAS.

Fig. 4 shows the results from different experiments to confirm the presence of spin diffusion in microcrystalline inorganic materials. If the surface and bulk spectra are distinctly different, the polarization transport from surface to bulk can be monitored with an experiment where hyperpolarization is transferred to nuclei near the surface of the particle with $\mathrm{CP}$, and then allowed to diffuse into the bulk during a waiting period $\left(\tau_{\mathrm{z}}\right)$ before detection (Fig. 4a). Fig. 4b shows that, for the ${ }^{119} \mathrm{Sn}$ spectra of $\mathrm{SnO}_{2}$, the bulk signal intensity increases as the delay is increased, while surface signals diminish. Additionally, spin diffusion and magnetization exchange pathways can be detected quantitatively with a two-dimensional exchange spectroscopy (EXSY) experiment, ${ }^{[18]}$ as shown in Fig. 4c and discussed in detail in ref. [19].

A change in the DNP enhancement $\varepsilon$ as a function of polarization delay has also been established to be a signature of relay. $[5,20]$ When enhancements are calculated at different relaxation delays, the result is that $\varepsilon$ changes with time in systems with relay. Examples of this are shown in Figs $4 \mathrm{~d}$ and $4 \mathrm{e}$, where hyperpolarization relay is observed between ${ }^{7} \mathrm{Li}$ nuclei in $\mathrm{Li}_{4} \mathrm{Ti}_{5} \mathrm{O}_{12}$ and between ${ }^{6} \mathrm{Li}$ nuclei in $\mathrm{Li}_{2} \mathrm{TiO}_{3}$. Note that the estimated $D$ for ${ }^{7} \mathrm{Li}-{ }^{7} \mathrm{Li}$ diffusion in $\mathrm{Li}_{4} \mathrm{Ti}_{5} \mathrm{O}_{12}$ is expected to be around 10 times higher than $D$ for ${ }^{6} \mathrm{Li}^{4}{ }^{6} \mathrm{Li}$ diffusion in $\mathrm{Li}_{2} \mathrm{TiO}_{3}$ (see Table 1), and that relay curve in Fig. 4e has not reached steady state. We also point out that although the lithium atoms themselves can diffuse in these materials, and polarization transfer could therefore either be mediated by physical diffusion or spin diffusion, lithium dynamics in these materials have been found to be relatively slow. ${ }^{[21]}$
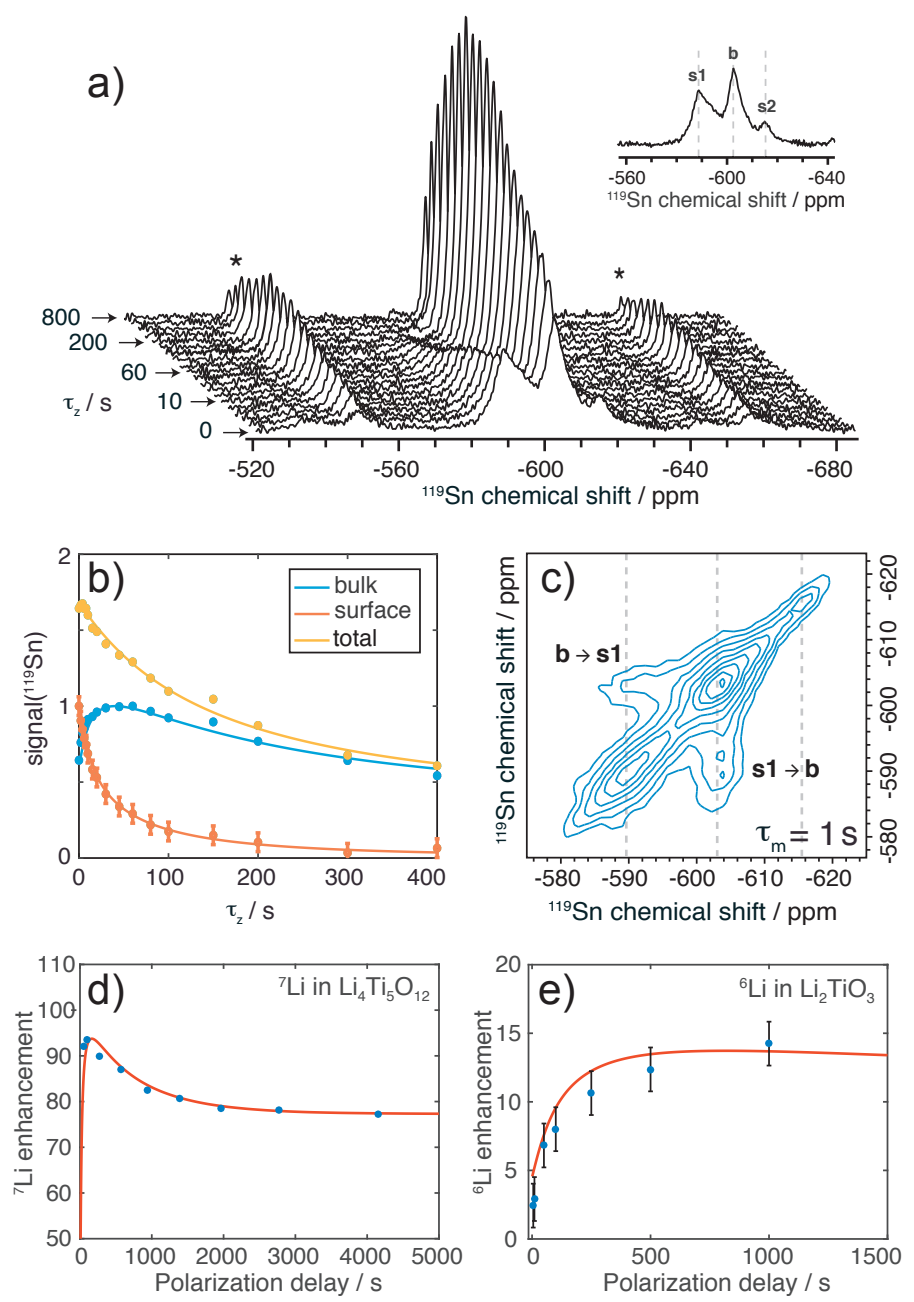

Fig. 4. Polarization relay in spinning samples. (a) Spin diffusion from surface to bulk in the DNP enhanced ${ }^{119} \mathrm{Sn}$ spectrum of $\mathrm{SnO}_{2}$. (b) Normalized surface, bulk and total signals of the spectra in a). (c) 2D CP spin diffusion exchange spectrum of $\mathrm{SnO}_{2}$. (d) ${ }^{7} \mathrm{Li}$ DNP enhancements in $\mathrm{Li}_{4} \mathrm{Ti}_{5} \mathrm{O}_{12}$ and $(\mathrm{e}){ }^{6} \mathrm{Li}$ enhancements in $\mathrm{Li}_{2} \mathrm{TiO}_{3}$ as a function of polarization delay. The solid lines are numerical simulations of polarization relay. Figure adapted from refs $[6 a, b, 19]$.

\section{Conclusions}

In conclusion, our recent work has shown that inorganic compounds such as lithium titanate can be efficiently hyperpolarized using impregnation DNP. We have discussed how homonuclear spin diffusion between weakly magnetic nuclei can be used as a mechanism for transporting surface-generated hyperpolarization into bulk. This has led to the development of a general strategy to improve the sensitivity of NMR signals of proton-free inorganic solids. 


\section{Acknowledgements}

S.B. would like to thank DSM and SCS for the award. The work presented here was supported by Swiss National Science Foundation Grant No. 200020_178860. We thank Brennan J. Walder, Pinelopi Moutzouri, Arthur C. Pinon, Nicolas Matthey, Pierrick Berruyer and Michael A. Hope for their contributions to some of the original work (see references).

Received: February 9, 2021

[1] B. Reif, S. E. Ashbrook, L. Emsley, M. Hong, Nat. Rev. Meth. Primers 2021, 1, 2, https://doi.org/10.1038/s43586-020-00002-1.

[2] a) R. Tycko, Аnпu. Rev. Phys. Chem. 2001, 52, 575 , https://doi.org/10.1146/annurev.physchem.52.1.575; b) K. J. D. MacKenzie, M. E. Smith, 'Multinuclear Solid-State NMR of Inorganic Materials', Elsevier Science: Oxford, UK, 2002; c) O. Pecher, J. CarreteroGonzalez, K. J. Griffith, C. P. Grey, Chem. Mater. 2017, 29, 213, https://doi.org/10.1021/acs.chemmater.6b03183; d) A. Kumar, B. J. Walder, A. Kunhi Mohamed, A. Hofstetter, B. Srinivasan, A. J. Rossini, K. Scrivener, L. Emsley, P. Bowen, J. Phys. Chem. C 2017, 121, 17188, https://doi.org/10.1021/acs.jpcc.7b02439; e) H. Al-Johani, E. Abou-Hamad, A. Jedidi, C. M. Widdifield, J. Viger-Gravel, S. S. Sangaru, D. Gajan, D. H. Anjum, S. Ould-Chikh, M. N. Hedhili, A. Gurinov, M. J. Kelly, M. El Eter, L. Cavallo, L. Emsley, J.-M. Basset, Nat. Chem. 2017, 9, 890, https://doi.org/10.1038/nchem.2752; f) M.A. Hope, T. Nakamura, P. Ahlawat, A. Mishra, M. Cordova, F. Jahanbakhshi, M. Mladenovic, R. Runjhun, L. Merten, A. Hinderhofer, B. I. Carlsen, D. J. Kubicki, R. Gershoni-Poranne, T. Schneeberger, L. C. Carbone, Y. Liu, S. M. Zakeeruddin, J. Lewinski, A. Hagfeldt, F. Schreiber, U. Rothlisberger, M. Grätzel, J. V. Milic, L. Emsley, J. Am. Chem. Soc. 2021, 143, 1529, https://doi.org/10.1021/jacs.0c11563.

[3] a) A. W. Overhauser, Phys. Rev. 1953, 91, 476, https://doi.org/10.1103/PhysRev.92.411; b) T. R. Carver, C. P. Slichter, Phys. Rev. 1953, 92, 212, https://doi.org/10.1103/PhysRev.92.212.2; c) Q. Z. Ni, E. Daviso, T. V. Can, E. Markhasin, S. K. Jawla, T. M. Swager, R. J. Temkin, J. Herzfeld, R. G. Griffin, Acc. Chem. Res. 2013, 46, 1933, https://doi.org/10.1021/ar300348n; d) A. S. L. Thankamony, J. J. Wittmann, M. Kaushik, B. Corzilius, Prog. Nucl. Magn. Reson. Spectroc. 2017, 102, 120, https://doi.org//10.1016/j.pnmrs.2017.06.002.

[4] a) A. Lesage, M. Lelli, D. Gajan, M. A. Caporini, V. Vitzthum, P. Miéville, J. Alauzun, A. Roussey, C. Thieuleux, A. Mehdi, G. Bodenhausen, C. Coperet, L. Emsley, J. Am. Chem. Soc. 2010, 132, 15459, https://doi.org/10.1021/ja104771z; b) A. J. Rossini, A. Zagdoun, M. Lelli, A. Lesage, C. Coperet, L. Emsley, Acc. Chem. Res. 2013, 46, 1942, https://doi.org/10.1021/ar300322x.

[5] a) P. C. A. van der Wel, K. N. Hu, J. Lewandowski, R. G. Griffin, J. Am. Chem. Soc. 2006, 128, 10840, https://doi.org/10.1021/ja0626685; b) A. J. Rossini, A. Zagdoun, F. Hegner, M. Schwarzwälder, D. Gajan, C. Copéret, A. Lesage, L. Emsley, J. Am. Chem. Soc. 2012, 134, 16899, https://doi.org/10.1021/ja308135r; c) A. C. Pinon, J. Schlagnitweit, P. Berruyer, A. J. Rossini, M. Lelli, E. Socie, M. Tang, T. Pham, A. Lesage, S. Schantz, L. Emsley, J. Phys. Chem. C 2017, 121, 15993, https://doi.org/10.1021/acs.jpcc.7b04438.

[6] a) S. Bjorgvinsdottir, B. J. Walder, A. C. Pinon, L. Emsley, J. Am. Chem. Soc. 2018, 140, 7946, https://doi.org/10.1021/jacs.8b03883; b) S. Bjorgvinsdottir, B. J. Walder, N. Matthey, L. Emsley, J. Magn. Reson. 2019, 300, 142, https:// doi.org/10.1016/j.jmr.2020.106888; c) S. Bjorgvinsdottir, P. Moutzouri, P. Berruyer, M. A. Hope, L. Emsley, J. Phys. Chem. C 2020, 124, 16524, https://doi.org/10.1021/acs.jpcc.0c05105.

[7] a) G. N. Zhu, Y. G. Wang, Y. Y. Xia, Energ. Environ. Sci. 2012, 5, 6652, https://doi.org/10.1039/C2EE03410G; b) G. J. Xu, P. X. Han, S. M. Dong, H. S. Liu, G. L. Cui, L. Q. Chen, Coord. Chem. Rev. 2017, 343, 139, https://doi.org/10.1016/j.ccr.2017.05.006.

[8] A. Pines, M. G. Gibby, J. S. Waugh, J. Chem. Phys. 1973, 59, 569, https://doi.org/10.1063/1.1680061.

[9] a) F. A. Perras, L.-L. Wang, J. S. Manzano, U. Chaudhary, N. N. Opembe, D. D. Johnson, I. I. Slowing, M. Pruski, Curr. Opin. Coll. Interf. Sci.
2018, 33, 9, https://doi.org/10.1016/j.cocis.2017.11.002; b) B. Itin, I. Sergeyev, 'Strategies for Efficient Sample Preparation for Dynamic Nuclear Polarization Solid-State NMR of Biological Macromolecules', in 'Protein NMR. Methods in Molecular Biology', Ed. R. Ghose, Humana Press, New York: NY, 2018; Vol. 1688; c) G. Casano, H. Karoui, O. Ouari, 'Polarizing Agents: Evolution and Outlook in Free Radical Development for DNP', in 'Handbook of High Field Dynamic Nuclear Polarization', Eds. V. K Michaelis, R. Griffin, B. Corzilius, S. Vega, John Wiley \& Sons: 2020; pp 103-120.

[10] a) L. R. Becerra, G. J. Gerfen, R. J. Temkin, D. J. Singel, R. G. Griffin, Phys. Rev. Lett. 1993, 71, 3561, https://doi.org/10.1103/PhysRevLett.71.3561; b) M. Rosay, M. Blank, F. Engelke, J. Magn. Reson. 2016, 264, 88, https://doi.org/10.1016/j.jmr.2015.12.026.

[11] a) A. Zagdoun, G. Casano, O. Ouari, M. Schwarzwalder, A. J. Rossini, F. Aussenac, M. Yulikov, G. Jeschke, C. Coperet, A. Lesage, P. Tordo, L. Emsley, J. Am. Chem. Soc. 2013, 135, 12790, https://doi.org/10.1021/ja405813t; b) A. Zagdoun, A. J. Rossini, D. Gajan, A. Bourdolle, O. Ouari, M. Rosay, W. E. Maas, P. Tordo, M. Lelli, L. Emsley, A. Lesage, C. Coperet, Chem. Commun. 2012, 48, 654, https://doi.org/10.1039/C1CC15242D.

[12] a) F. A. Perras, T. Kobayashi, M. Pruski, 'Growing Signals from the Noise: Challengin Nuclei in Materials DNP', in 'Handbook of High Field Dynamic Nuclear Polarization', Eds. V. K. Michaelis, R. G. Griffin, B. Corzilius, S. Vega, John Wiley \& Sons: 2020; b) P. Berruyer, L. Emsley, A. Lesage, 'DNP in Materials Science: Touching the Surface', in 'The Handbook of High Field Dynamic Nuclear Polarization', Eds. V. K. Michaelis, R. G. Griffin, B. Corzilius, S. Vega, John Wiley \& Sons: 2020; pp 337-352; (c) A. J. Rossini, J. Phys. Chem. Lett. 2018, 9, 5150, https://doi.org/10.1021/acs.jpclett.8b01891.

[13] a) N. Bloembergen, Physica XV 1949, 3-4, 386; b) M. Ernst, B. Meier, 'Spin diffusion in solids', in 'Solid State NMR of Polymers', Eds. I. Ando, T. Asakura, Elsevier Science B.V.: 1998; Vol. 84, pp 83-121.

[14] W. Zhang, D. G. Cory, Phys. Rev. Lett. 1998, 80, 1324, https://doi.org/10.1103/PhysRevLett.80.1324.

[15] G. R. Khutsishvili, Sov. Phys. Usp. 1966, 8, 743

[16] a) S. Clough, K. W. Gray, Proc. Phys. Soc. 1962, 79, 457; b) M. M. Maricq, J. S. Waugh, J. Chem. Phys. 1979, 70, 3300, https://doi.org/10.1063/1.437915; c) M. E. Halse, A. Zagdoun, J. N. Dumez, L. Emsley, J. Magn. Reson. 2015 254, 48, https://doi,.org/10.1016/j.jmr.2015.02.016.

[17] a) A. J. Rossini, A. Zagdoun, M. Lelli, D. Gajan, F. Rascón, M. Rosay, W. E. Maas, C. Copéret, A. Lesage, L. Emsley, Chem. Sci. 2012, 3, 108 , https://doi.org/10.1039/C1SC00550B; b) T. Kobayashi, O. Lafon, A. S. L. Thankamony, I. I. Slowing, K. Kandel, D. Carnevale, V. Vitzthum, H. Vezin, J. P. Amoureux, G. Bodenhausen, M. Pruski, Phys. Chem. Chem. Phys. 2013, 15, 5553, https://doi.org/10.1039/C3CP00039G; (c) D. Lee, S. Hediger, G. De Paepe, Solid State Nucl. Magn. Reson. 2015, 66-67, 6 , https://doi.org/10.1016/j.ssnmr.2015.01.003.

[18] J. Jeener, B. H. Meier, P. Bachmann, R. R. Ernst, J. Chem. Phys. 1979, 71, 4546, https://doi.org/10.1063/1.438208.

[19] S. Björgvinsdóttir, P. Moutzouri, B. J. Walder, N. Matthey, L. Emsley, J. Magn. Reson. 2021,323, 106888, https://doi.org/10.1016/j.jmr.2020.106888.

[20] N. A. Prisco, A. C. Pinon, L. Emsley, B. F. Chmelka, Phys. Chem. Chem. Phys. 2021, 23, 1006, https://doi.org/10.1039/D0CP03195J.

[21] a) W. Schmidt, M. Wilkening, Solid State Ionics 2016, 287, 77, https://doi.org/10.1016/j.ssi.2016.02.012; b) B. Ruprecht, M. Wilkening, R. Uecker, P. Heitjans, Phys. Chem. Chem. Phys. 2012, 14, 11974, https://doi.org/10.1039/C2CP41662J.

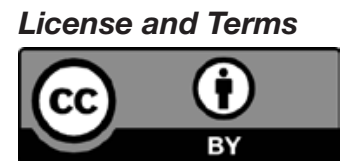

This is an Open Access article under the terms of the Creative Commons Attribution License CC BY 4.0. The material may not be used for commercial purposes.

The license is subject to the CHIMIA terms and conditions: (http:// chimia.ch/component/sppagebuilder/?view=page \&id=12).

The definitive version of this article is the electronic one that can be found at https://doi.org/10.2533/chimia.2021.333 